\title{
Determinação do módulo de elasticidade \\ em aços e alumínio através da frequência natural comparado ao ensaio de tração
}

\author{
Determination of the elasticity module in \\ steels and aluminum through the natural \\ frequency compared to the tension test
}

Mateus Henrique Mezzomo ${ }^{1}$, Amauri Gomes de Moraes ${ }^{1}$

\author{
${ }^{1}$ Universidade de Passo Fundo (UPF), ROD BR 285, KM 292,7 - CEP: 99052-900, Campus I, São José, Passo Fundo, \\ RS, Brasil. \\ e-mail: mateusmezzomo@gmail.com, amauri@upf.br
}

\begin{abstract}
RESUMO
Muitos materiais, quando em serviço, são submetidos a forças ou cargas. Nestas situações é necessário conhecer as propriedades do material, dentre estas o módulo de elasticidade, para se projetar peças e dispositivos, de forma que qualquer deformação resultante seja previsível e não o suficiente para ocorrer deformações plásticas, fadiga acelerada ou até mesmo a fratura. Neste artigo foi utilizado um método dinâmico para determinar o módulo de elasticidade de uma liga de alumínio e de dois tipos de aços medindose a frequência natural de vibração, sem a necessidade de destruir o corpo de prova, como em ensaios de tração por exemplo. O procedimento experimental consistiu em submeter o material a impactos controlados, para obter as frequências naturais por meio de um acelerômetro. Com os resultados das frequências, utilizando-se de meios matemáticos propostos pela norma ASTM E 1876, pode-se definir o módulo de elasticidade do material. Este procedimento pode identificar o módulo de elasticidade do material de uma maneira não-destrutiva, rápida e de boa confiabilidade. Com a intensão de obter parâmetros que possam gerar um nível de confiabilidade nos ensaios, foi realizada a comparação dos resultados deste experimento com os resultados obtidos no ensaio de tração, onde a diferença do aço Domex 700 entre os métodos foi de 3,22\%, a diferença do aço SAE 1522 foi de 1,68\% e a diferença da liga de alumínio $1200 \mathrm{H} 14$ foi de 6,27\%, mostrando assim que o método é válido e que os resultados foram semelhantes.
\end{abstract}

Palavras chave: Módulo de elasticidade; Frequência natural; Ensaio de tração.

\begin{abstract}
Many materials, when in service, are subjected to forces or loads. In these situations it is necessary to know the material properties, among them the elasticity modulus, to design parts and devices, so that any resulting deformation is predictable and not enough to occur plastic deformations, accelerated fatigue or even fracture. In this paper a dynamic method was used to define the elasticity modulus of an aluminum alloy and two types of steel measuring the natural frequency of vibration without the need to destroy the specimen, as in tensile tests for example. The experimental procedure consisted of subjecting the material to controlled impacts to obtain the natural frequencies through an accelerometer. With the frequency results, by mathematical means proposed by ASTM E 1876, the material's elasticity modulus can be defined. This procedure can identify the material's elasticity modulus in a non-destructive, fast and reliable manner. With the intention of obtaining parameters that can generate a level of reliability in the tests, the results of this experiment were compared with the results obtained in the tensile test, where the difference of Domex 700 steel between the methods was $3.22 \%$, SAE 1522 steel difference was $1.68 \%$ and the $1200 \mathrm{H} 14$ aluminum alloy difference was $6.27 \%$, showing that the method is valid and the results were similar.
\end{abstract}

Keywords: Elasticity Modulus; Natural Frequency; Tensile Test.

\section{INTRODUÇÃO}

Conhecer o módulo de elasticidade dos materiais é importante para o dimensionamento de várias estruturas estáticas ou dinâmicas submetidas as mais diversas aplicações. Portanto, é necessário ter coerência no modo 
com o qual os ensaios são realizados e na interpretação de seus resultados utilizando técnicas de ensaios de materiais padronizadas e publicadas anualmente por sociedades reconhecidas como a ABNT e a ASTM [2].

Segundo CALLISTER [1], os materiais são geralmente selecionados para aplicações estruturais, por terem características e combinações desejáveis, como a resistência mecânica, a durabilidade e a rigidez. Os engenheiros devem determinar as tensões e as distribuições das mesmas, podendo ser obtida através de técnicas experimentais ou de análises teóricas e matemáticas de tensão que necessitam do conhecimento dos módulos elásticos. Os materiais devem ser fabricados para atender as exigências de serviços como previsto por essas análises de tensão. Portanto, é indispensável entender as propriedades mecânicas dos materiais, que estão diretamente ligadas aos módulos de elasticidade que, por sua vez, estão correlacionados à descrição de várias outras propriedades mecânicas, como por exemplo, as tensões de ruptura e de escoamento.

$\mathrm{O}$ artigo aborda um método não destrutivo para determinar o módulo de elasticidade através da frequência natural de vibração, com base na norma ASTM E 1876 [2]. O procedimento consiste em submeter o material a impactos controlados e com o auxílio de dispositivos eletrônicos de captação e análise de sinal determinar as frequências naturais de vibração. Para a leitura das vibrações e o pós-processamento dos dados coletados foi utilizado um programa de aquisição de dados e para obtenção das frequências naturais foi empregada a Transformada da Rápida de Fourier (FFT). Com os resultados das frequências naturais, através de meios matemáticos propostos pela norma ASTM E 1876, foi possível determinar o módulo de elasticidade de cada material de uma maneira rápida e não destrutiva.

Para realizar os ensaios, foram utilizados três corpos de prova: um de aço Domex 700, um de aço SAE 1522 e um de alumínio $1200 \mathrm{H} 14$. A fim de se obter um nível de confiança o método da norma ASTM E 1876 foi comparado com o ensaio de tração, apresentando vantagens em relação aos resultados obtidos.

Os autores ALMEIDA et. al. [3] mediram o módulo de cisalhamento dinâmico com base no método de vibração livre e, os autores BATISTA et. al. [4] usaram a excitação por impulso de vibração para determinar o módulo de Young a partir da frequência natural, usando uma amostra retangular no modo de flexão. BEZERRA et. al.[5] pesquisaram a influência do adensamento do concreto nos valores de resistência à compressão e de módulo de elasticidade obtidos pelo ensaio estático e dinâmico por frequência ressonante.

\subsection{Norma ASTM E 1876}

Compreende o método de teste padrão para módulo de elasticidade dinâmico, módulo de cisalhamento e razão de Poisson pela excitação de vibração por impulso [2]. O método determina as propriedades elásticas dinâmicas de materiais elásticos à temperatura ambiente. Os materiais possuem frequências de ressonância mecânica que são determinadas pelo módulo de elasticidade, pela massa e a geometria do corpo de prova. As propriedades elásticas dinâmicas de um material podem ser calculadas, se a geometria, a massa e as frequências de ressonância mecânica de uma amostra poderem ser medidas. O módulo de elasticidade dinâmico é determinado utilizando a frequência de ressonância de vibração em flexão.

\subsubsection{Método de Teste}

Este método obtém a frequência de ressonância fundamental em corpos de prova excitando-os mecanicamente com o auxílio de um martelo utilizado como ferramenta de impulso. Um acelerômetro de contato mede as vibrações mecânicas no corpo de prova e as transforma em sinais elétricos. Estes sinais são analisados e a frequência natural é isolada e medida pelo analisador de sinais que fornece uma leitura numérica proporcional à frequência de vibração da amostra utilizada para calcular o módulo de elasticidade [2]. O aparelho, Figura 1, deve detectar com precisão, analisando e medindo a frequência natural.

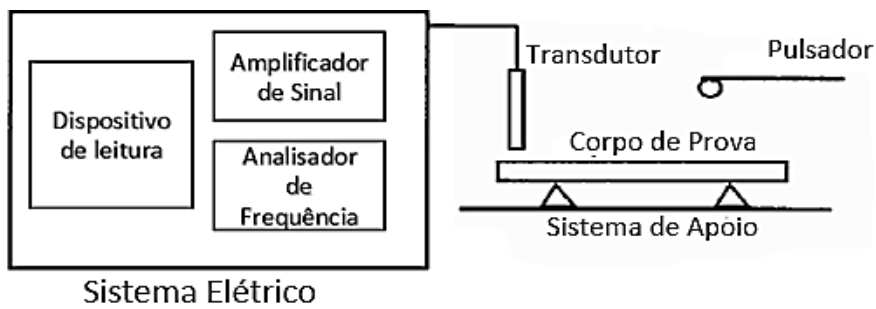

Figura 1: Aparelho típico de ensaio [2].

\subsubsection{Vibração Flexional de barras}

As frequências flexionais surgem quando um corpo de prova no formato de barra encontra-se apoiado em seus pontos nodais $(0,224 \mathrm{~L})$ e o mesmo sofre um impacto no centro ou nas extremidades, não somente pelo 
comprimento e seção transversal, mas pela razão entre os dois [2]. A Figura 2 mostra o modelo de vibração flexional de uma barra de secção retangular, conforme a norma ASTM E 1876 [2].

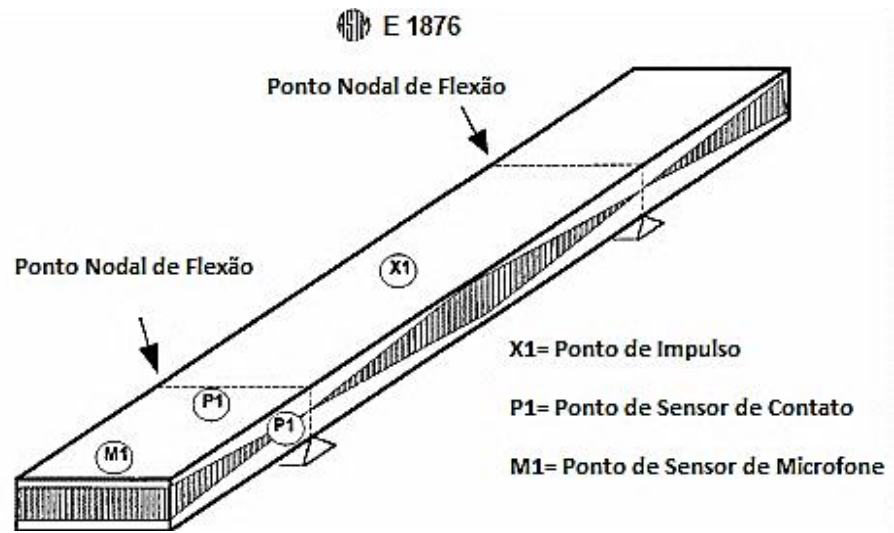

Figura 2: Modo de vibração flexional para uma barra de seção retangular [2].

\section{Pulsador}

O impulso de excitação é caracterizado por levemente golpear a amostra. Esta ferramenta deve ter a maior massa concentrada no ponto de impacto e ter massa suficiente para induzir uma vibração mecânica mensurável, mas não tão grande para deslocar ou danificar a amostra. Exemplo de pulsador é uma esfera de aço de $0,5 \mathrm{~cm}$ de diâmetro colada à extremidade de uma haste de polímero flexível de $10 \mathrm{~cm}$ [2], sendo este o modelo de pulsador utilizado nos ensaios.

\section{Captura de Sinais}

Conforme a norma ASTM E 1876 [2], a detecção do sinal pode ser realizada pelo uso de transdutores em contato direto com a amostra como acelerômetros piezoeléctricos ou extensômetros. O alcance do transdutor de frequência deve ser suficiente para medir as frequências esperadas das amostras. A resposta do transdutor em toda a gama de frequências de interesse deve ter uma largura de banda de pelo menos $10 \%$ da frequência máxima medida antes de ocorrer perda de potência de $-3 \mathrm{~dB}$.

\section{Sistema Eletrônico}

Para a norma ASTM E 1876 [2]], o sistema eletrônico consiste em um condicionador/amplificador de sinal, analisador de sinal e um dispositivo de leitura de frequência. O sistema deve ter exatidão suficiente para medir as frequências de interesse com precisão de $0,1 \%$. O sinal do condicionador/amplificador deve ser adequado para alimentar o transdutor e proporcionar um sinal amplificado apropriado para o analisador de sinal. O sistema de análise de sinal consiste de um dispositivo de contagem de frequência e um dispositivo de leitura. Com o auxílio de um osciloscópio de armazenamento digital, um sistema de análise do sinal pela Transformação Rápida de Fourier pode ser útil para identificar a frequência de ressonância fundamental.

\section{Sistema de Apoio}

O apoio serve para isolar a amostra de vibração estranha sem restringir o modo desejado de vibração da amostra. Materiais de apoio podem ser macios ou rígidos para condições ambientais. Materiais macios podem ser tiras de espuma de poliuretano com superfícies planas. Materiais rígidos, como metal ou cerâmica, deverão ter bordas faca afiadas ou superfícies cilíndricas e devem ser apoiados em almofadas de isolamento para evitar a captura de vibrações ambientais pelo transdutor [2].

\subsubsection{Teste da amostra}

A norma ASTM E 1876 [2], traz algumas recomendações para a execução dos testes:

$>$ A seleção do tamanho da amostra deve ser feita de modo que, por estimativa, a frequência de ressonância medida seja compatível com o intervalo de resposta dos transdutores e do sistema eletrônico;

$>$ Todas as superfícies sobre a amostra retangular devem ser planas;

> Massa, comprimento, espessura e largura das amostras devem ser determinadas com precisão de $0,1 \%$; 
A espessura e largura da peça retangular devem ser medidas com uma precisão de $0,1 \%$ em três locais e uma média determinada.

\subsection{Vibrações}

Conforme RAO [6], todo movimento que se repete após um intervalo de tempo é chamado de vibração ou oscilação. A vibração de um sistema abrange a transferência alternada de energia potencial para energia cinética e de energia cinética para potencial.

Segundo BOROBIA [7], os termos movimento, oscilação e vibração não são sinônimos. Toda vibração é uma oscilação e toda oscilação é um movimento, mas esta afirmação não deve ser feita no sentido inverso. Portanto, uma roda se move, mas não oscila, e um pêndulo simples oscila, mas não vibra.

O conceito de vibração pode ser conhecido através do conceito de energia. As oscilações e as vibrações se prolongam no tempo por meio de um processo de conversão entre distintos tipos de energia. Logo, para que se possa falar de vibração de um sistema mecânico é necessário aparecer a energia de deformação ou a energia potencial elástica [7].

A frequência natural, para RAO [6], é um fenômeno que acontece se um sistema, após uma perturbação inicial, é deixado para vibrar por si próprio, a frequência com a qual ele oscila sem a presença de forças externas é denominada de frequência natural.

De acordo com RAO [6], interpreta-se como ressonância mecânica a tendência do sistema físico em oscilar na sua máxima amplitude. Esta tendência depende da aproximação da frequência de excitação das frequências naturais do sistema. Estas frequências, mesmo as de pequena amplitude de excitação, são capazes de produzir elevadas amplitudes de vibração no sistema, sendo possível até levar ao seu colapso. Para BOROBIA [7] a presença de grandes deslocamentos é um fenômeno indesejável uma vez que provoca a aparição de tensões e deformações igualmente grandes que podem acarretar na falha do sistema.

\subsection{Módulo de Elasticidade}

CALLISTER [1], define que o módulo de elasticidade é a rigidez ou a resistência do material à deformação elástica. Quanto maior for este módulo mais rígido será o material e menor será a deformação elástica resultante de uma tensão. Para aços é próximo de $207 \mathrm{GPa}$ e para o alumínio de $69 \mathrm{GPa}$.

De acordo com GARCIA et. al. [8], o módulo de elasticidade pode ser determinado através das forças de ligação entre os átomos de um metal. Como essas forças são constantes, o módulo de elasticidade é considerado uma propriedade constante nos materiais, apesar de ser levemente afetado por adições de elementos de liga, ou por variações alotrópicas, tratamentos térmicos ou trabalho a frio que alterem a estrutura metálica.

A lei de Hooke estabelece que o módulo de elasticidade é a razão entre a tensão e a deformação relativa, dentro do limite elástico, onde a deformação é proporcional à tensão representado pelo ângulo $\theta$ [1], de acordo com a Figura 3.

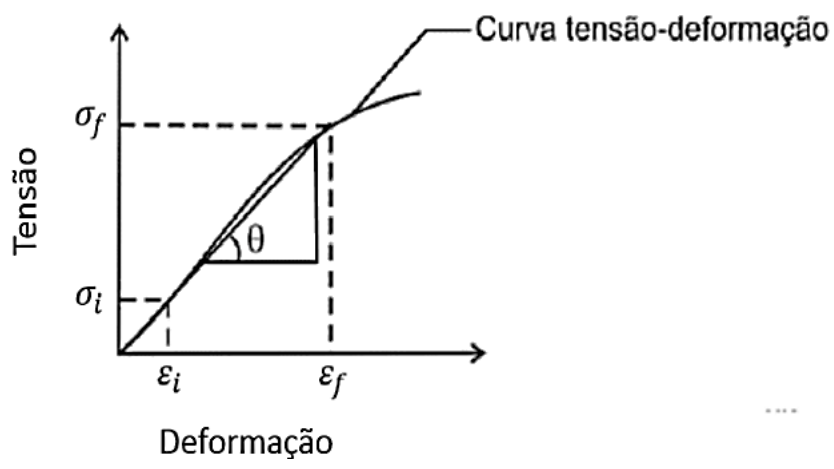

Figura 3: Diagrama esquemático da tensão-deformação [1]

\subsection{Acelerômetro}

Para ALIATORE [9], um acelerômetro é um sensor projetado para medir a aceleração, ou a taxa de variação da velocidade devido ao movimento, vibração e eventos de impacto. Acelerômetros são normalmente fixados mecanicamente a um objeto ou estrutura na qual se quer medir a aceleração ao longo de um eixo sendo insensível ao movimento nas direções ortogonais. 
De acordo com FIGUEIREDO, et al. [10], os acelerômetros podem ser separados em capacitivos, piezoelétricos e micro acelerômetros (MEMS). Os MEMS são sensíveis, compactos, baratos e capazes de medir a aceleração e a vibração em um, dois ou três eixos. O sensor MENS é baseado no movimento de uma estrutura em silício. A aceleração é obtida pela medição dos deslocamentos de elementos móveis que estão associados aos eixos e, posteriormente, é convertida em sinal analógico ou digital.

\subsection{Amplificador de Sinal}

A impedância de saída de um transdutor não é adequada para a entrada direta no equipamento de análise de sinal, são usados condicionadores de sinal na forma de amplificadores de carga ou tensão, para comparar e amplificar os sinais antes da análise [6]. Um exemplo é o HBM MGCplus, um amplificador de sinal para aquisição de dados (DAQ) da empresa HBM, que suporta amplo espectro de transdutores além de conexões e interfaces para computadores. O programa Catman gerencia a aquisição dos dados [11].

\subsection{Transformada rápida de Fourier (FFT)}

Conforme RAO [6], o sinal de resposta de uma frequência após ser condicionado é enviado a um analisador para processamento. $\mathrm{O}$ analisador recebe sinais analógicos de tensão (que representam deslocamento, velocidade, aceleração, deformação ou força) de um amplificador, filtro e digitalizador condicionador de sinal, para executar cálculos. Ele calcula os espectros de frequência discreta de sinais individuais, bem como espectros cruzados entre a entrada e os diferentes sinais de saída. Os sinais analisados são usados para determinas às frequências naturais, de amortecimento e as formas modais em forma numérica ou gráfica.

\section{MATERIAIS E MÉTODOS}

Desejando estabelecer uma base sólida, coerente e sistemática que seja capaz de dirigir o estudo, este trabalho foi organizado de acordo com as etapas descritas no fluxograma da Figura 4.

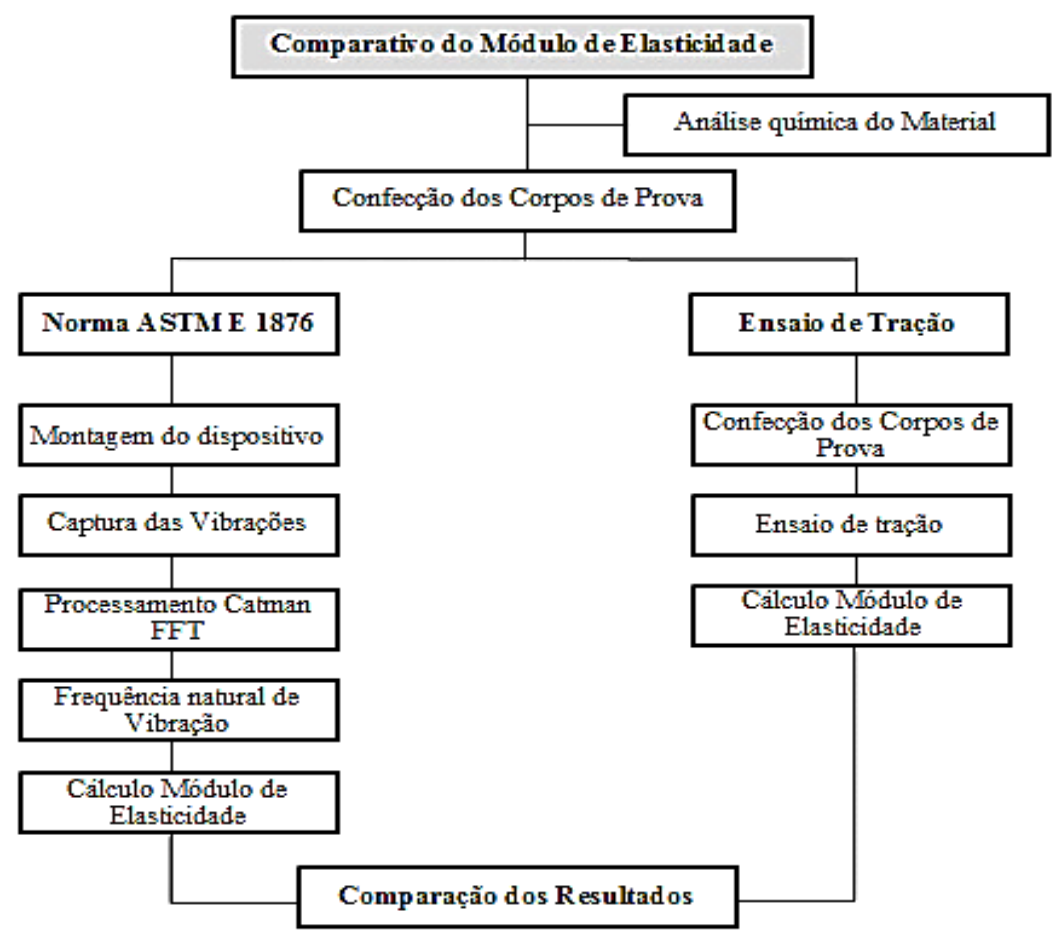

Figura 4: Etapas para o desenvolvimento do trabalho.

\subsection{Confecção dos corpos de prova e análise química do material}

Para realizar o experimento, foram separadas as amostras do aço Domex 700, do aço SAE 1522 e do Alumínio $1200 \mathrm{H} 14$ e preparado um corpo de prova para cada material. As dimensões estão listadas na Tabela 1 e o desenho de um dos corpos de prova para ensaio da Frequência Natural está mostrado na Figura 5. Os corpos de prova foram cortados, fresados e retificados, para ficarem nas dimensões indicadas pela norma ASTM E 1876 [2]. 
Tabela 1: Dimensões dos Corpos de Prova para ensaio da Frequência Natural

\begin{tabular}{c|c|c|c}
\hline & Aço Domex 700 & Aço SAE 1522 & Alumínio \\
\hline Comprimento & $250 \mathrm{~mm}$ & $250 \mathrm{~mm}$ & $250 \mathrm{~mm}$ \\
Largura & $70 \mathrm{~mm}$ & $70 \mathrm{~mm}$ & $70 \mathrm{~mm}$ \\
Espessura & $9,3 \mathrm{~mm}$ & $7,9 \mathrm{~mm}$ & $2,5 \mathrm{~mm}$ \\
\hline
\end{tabular}

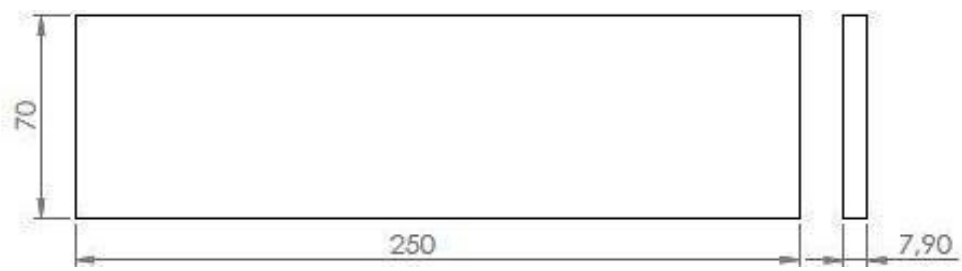

Figura 5: Corpo de prova para Ensaio da Frequência Natural do aço SAE 1522.

A composição química do material foi analisada por um espectrômetro de emissão óptica FOUNDRY-MASTER, modelo Xline. O procedimento foi realizado três vezes e ao final obteve-se a média dos elementos químicos da amostra analisada. A Tabela 2 mostra os valores, em porcentual, dos principais elementos encontrados na análise da composição química para as chapas de aço Domex 700 e aço SAE 1522.

Tabela 2: Principais elementos na composição química dos aços Domex 700 e SAE 1522

\begin{tabular}{c|c|c|c|c|c|c|c|c|c|c|c|c}
\hline & $\mathrm{C}$ & $\mathrm{Si}$ & $\mathrm{Mn}$ & $\mathrm{P}$ & $\mathrm{S}$ & $\mathrm{Cr}$ & $\mathrm{Mo}$ & $\mathrm{Ni}$ & $\mathrm{Al}$ & $\mathrm{Co}$ & $\mathrm{Cu}$ & $\mathrm{Nb}$ \\
\hline Domex & 0,067 & 0,037 & 1,76 & 0,013 & 0,001 & 0,028 & 0,087 & 0,033 & 0,035 & 0,015 & 0,016 & 0,046 \\
SAE 1522 & 0,196 & 0,272 & 1,27 & 0,016 & 0,011 & 0,014 & 0,003 & 0,010 & 0,030 & 0,003 & 0,015 & 0,024 \\
\hline
\end{tabular}

A Tabela 3 exibe os valores em porcentagem dos principais elementos encontrados na análise de composição química realizada na chapa de Alumínio.

Tabela 3: Principais elementos na composição química do Alumínio $1200 \mathrm{H} 14$

\begin{tabular}{c|c|c|c|c|c|c|c|c|c|c|c}
\hline $\mathrm{Al}$ & $\mathrm{Si}$ & $\mathrm{Mn}$ & $\mathrm{Fe}$ & $\mathrm{Cu}$ & $\mathrm{Mg}$ & $\mathrm{Cr}$ & $\mathrm{Ni}$ & $\mathrm{Ti}$ & $\mathrm{V}$ & $\mathrm{Zn}$ & $\mathrm{Pb}$ \\
\hline 96,1 & 0,115 & 0,035 & 0,278 & 0,015 & 3,10 & 0,19 & 0,026 & 0,026 & 0,019 & 0,006 & 0,014 \\
\hline
\end{tabular}

\subsection{Montagem do Dispositivo baseado na norma ASTM E1876 e realização dos ensaios}

De acordo com a norma ASTM E 1876, o dispositivo completo para a realização dos ensaios, Figura 6, foi montado no laboratório de projeto mecânico no núcleo de tecnologia da Universidade de Passo Fundo.

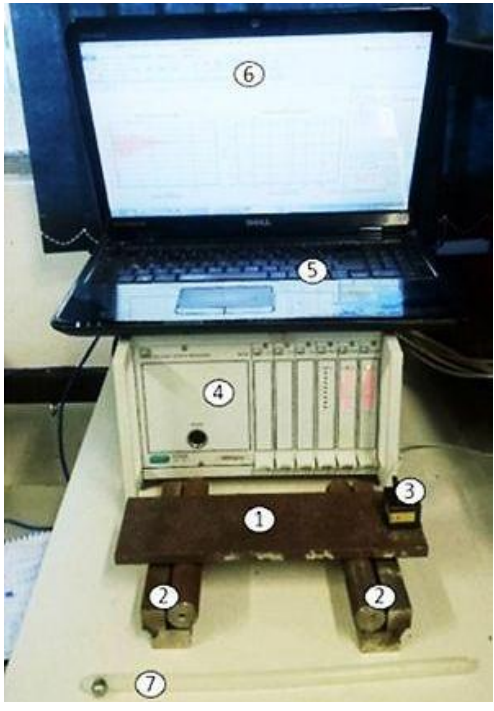

\begin{tabular}{|l|l|}
\hline 1 & Peça \\
\hline 2 & Apoios \\
\hline 3 & Acelerômetro \\
\hline 4 & Amplificador de Sinal \\
\hline 5 & Notebook \\
\hline 6 & Programa Catman \\
\hline 7 & Martelete \\
\hline
\end{tabular}

Figura 6: Dispositivo para Ensaio baseado na norma ASTM E 1876 
A peça foi apoiada em dois suportes dispostos sobre uma superfície plana de EVA. As medidas para a colocação dos apoios foram tomadas pela norma ASTM E $1876 \mathrm{com}$ distância de 0,224L das extremidades da peça até o centro dos apoios. Um acelerômetro tipo MEMS, marca Silicon Designs, foi fixado numa das extremidades da peça e conectado na interface do amplificador HBM modelo MGCplus, ligado a um notebook, capturou as frequências naturais das amostras através do programa Catman.

Foi utilizado o martelete (item 7 da Figura 6) para realizar o impulso e produzir a frequência natural de vibração. Foram realizados cinco impulsos no lado oposto ao local onde o acelerômetro foi instalado.

Terminado os ensaios, foi feito o pós-processamento no programa Catman, onde o gráfico das vibrações de cada ensaio foi analisado para obter o valor da frequência natural em $\mathrm{Hz}$ através da Transformada Rápida de Fourier. Em seguida, foi calculada a média das frequências dos cinco ensaios realizados em cada material, obtendo a frequência de ressonância fundamental de flexão e, a partir da frequência de cada amostra foi calculado, através da Equação 1, o módulo de elasticidade de cada material.

$$
E=0.9465\left(\frac{m f_{f}^{2}}{b}\right)\left(\frac{L^{3}}{t^{3}}\right) T_{1}
$$

Onde:

$\mathrm{E}=$ Módulo de Elasticidade, $(\mathrm{Pa})$

$\mathrm{m}=$ Massa da amostra, $(\mathrm{g})$

$\mathrm{b}=$ Largura da amostra, $(\mathrm{mm})$

$\mathrm{L}=$ Comprimento da amostra, $(\mathrm{mm})$

$\mathrm{t}=$ Espessura da amostra, $(\mathrm{mm})$

$f_{f}=$ Frequência de ressonância fundamental da amostra, $(\mathrm{Hz})$

$T_{1}=$ Fator de correção para o modo de flexão fundamental

Para determinar o fator de correção para o modo de flexão fundamental $T_{1}$ é utilizada a Equação 2 se a relação $L / t \geq 20$, caso contrário deve se verificar outras equações descritas na norma ASTM E1876.

$$
T_{1}=\left[1.000+6.585(t / L)^{2}\right]
$$

\section{3 Ensaio de Tração}

Para este procedimento, foram utilizados os corpos de prova para realizar os ensaios pelo método da frequência natural por impulso. Três corpos de prova de cada material foram cortados em uma máquina de corte por jato de água conforme apresentados na Figura 7, de acordo com a norma ASTM E 8M [12].

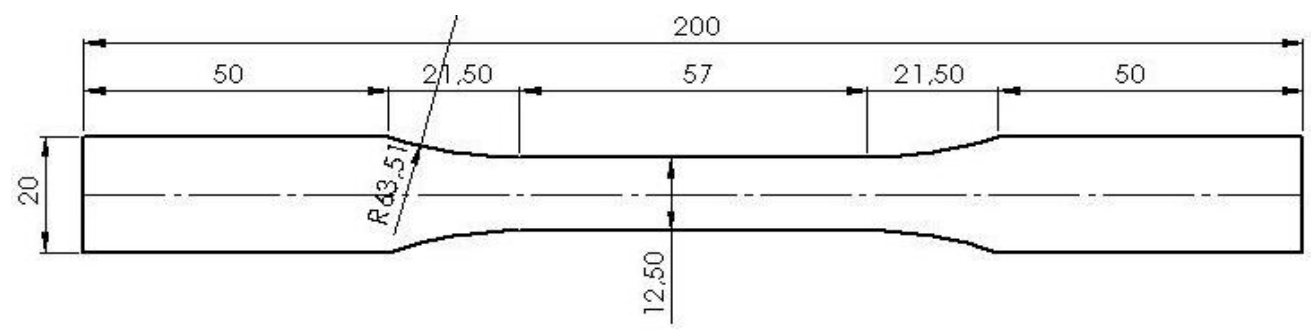

Figura 7: Modelo dos corpos de prova utilizados para o ensaio de Tração

Os ensaios de tração foram realizados na máquina universal de ensaios mecânicos da marca Schenck, com capacidade de $200 \mathrm{KN}$. Inicialmente, o comprimento inicial da seção reduzida foi medido, em seguida os corpos de prova foram fixados na máquina e uma carga com avanço constante foi aplicada até a ruptura. Depois de romper, a seção reduzida foi novamente medida e os valores inseridos no programa da máquina. Finalmente, o módulo de elasticidade foi calculado aplicando os resultados do ensaio de tração na Equação 3.

$$
\mathrm{E}=\frac{\sigma}{\varepsilon}
$$

Onde: E é o módulo de elasticidade; $\sigma$ é a tensão e $\varepsilon$ é a deformação. 
Para o cálculo da tensão foi utilizada a Equação 4.

$\sigma=\frac{F}{A_{0}}$

Onde: F é a força instantânea aplicada e $A_{0}$ é a área original.

Para o cálculo da deformação foi utilizada a Equação 5.

$\varepsilon=\frac{\Delta L}{L_{0}}$

Onde: $\Delta L$ é o alongamento da deformação e $L_{0}$ é o comprimento original.

\section{RESULTADOS}

\subsection{Método da frequência natural de vibração baseado na norma ASTM E 1876}

Com os ensaios realizados pelo método de cálculo da frequência natural por impulso, foi possível obter os resultados mostrados a seguir. Através do programa de aquisição de dados, pode ser observado em cada amostra, as oscilações da frequência natural de vibração do metal causado pelo pulsador. A Figura 8 mostra o valor encontrado de 796,9 Hz para a frequência natural no aço Domex 700.

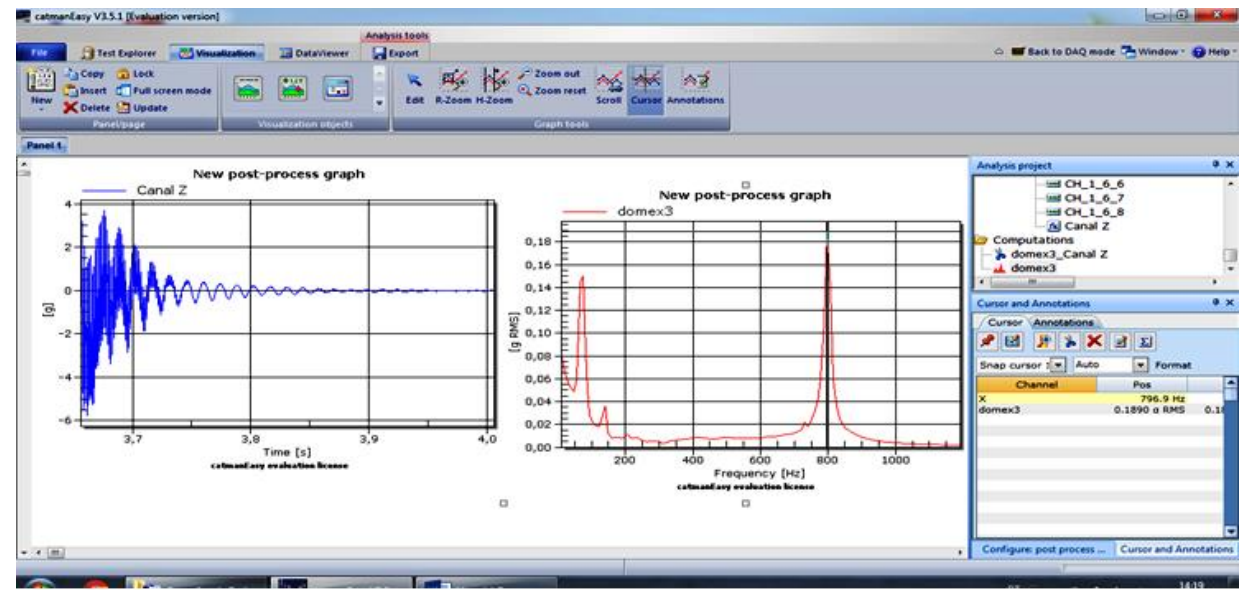

Figura 8: Resultado encontrado da frequência natural no Aço Domex 700

A Figura 9 mostra o valor de 656,3 Hz encontrado para a frequência natural no aço SAE 1522.

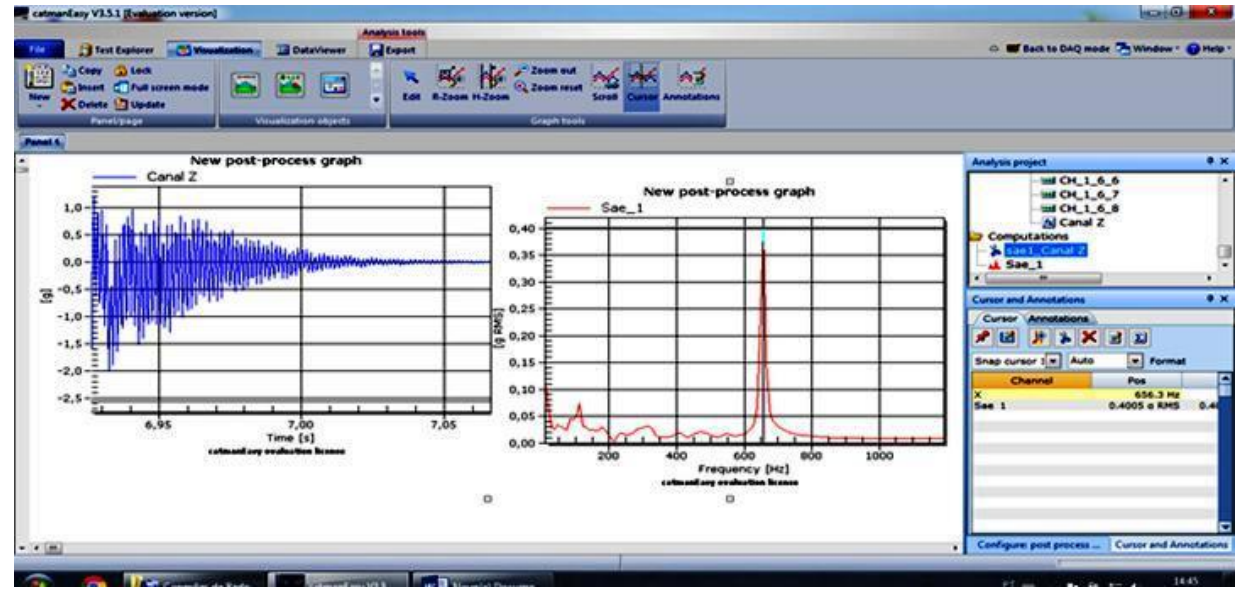

Figura 9: Resultado encontrado da frequência natural no Aço SAE 1522

A Figura 10 mostra o valor de $187,5 \mathrm{~Hz}$ encontrado para a frequência natural no Alumínio. 


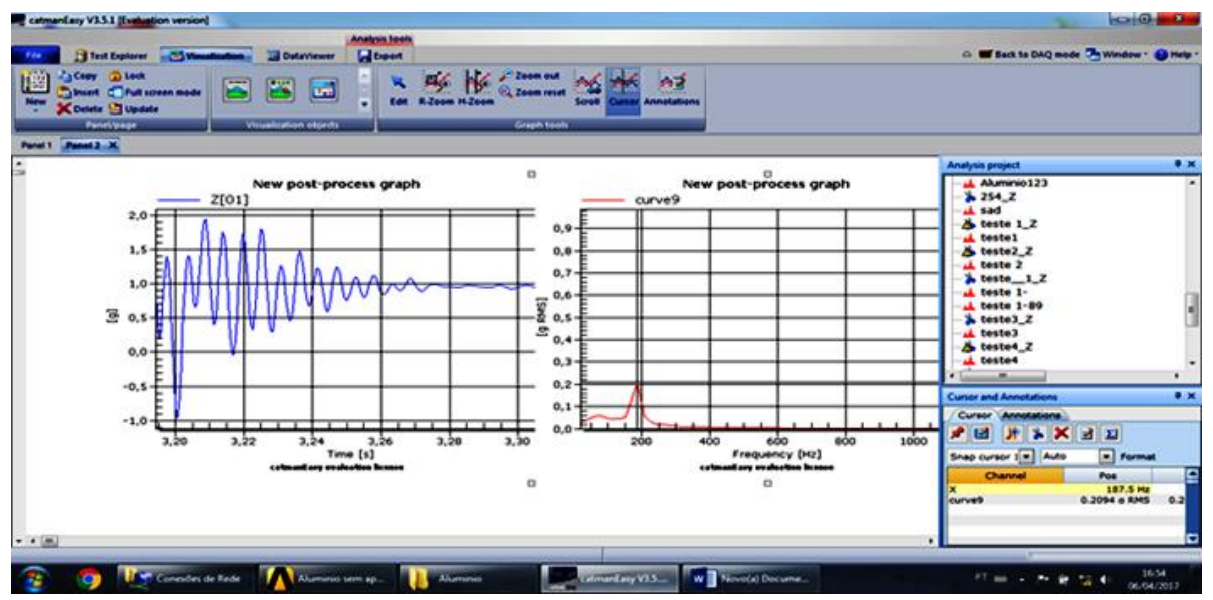

Figura 10: Resultado encontrado da frequência natural no Alumínio 1200H14.

Na Tabela 4 estão os valores e a média das frequências naturais relativos aos cinco ensaios para cada amostra.

Tabela 4: Valores encontrados das frequências naturais de vibração dos materiais

\begin{tabular}{c|c|c|c}
\hline Ensaio & Aço Domex 700 & Aço SAE 1522 & Alumínio \\
\hline Ensaio 1 & $796,9 \mathrm{~Hz}$ & $656,3 \mathrm{~Hz}$ & $187,5 \mathrm{~Hz}$ \\
Ensaio 2 & $796,9 \mathrm{~Hz}$ & $656,3 \mathrm{~Hz}$ & $187,5 \mathrm{~Hz}$ \\
Ensaio 3 & $796,9 \mathrm{~Hz}$ & $656,3 \mathrm{~Hz}$ & $187,5 \mathrm{~Hz}$ \\
Ensaio 4 & $796,9 \mathrm{~Hz}$ & $656,3 \mathrm{~Hz}$ & $187,5 \mathrm{~Hz}$ \\
Ensaio 5 & $796,9 \mathrm{~Hz}$ & $656,3 \mathrm{~Hz}$ & $187,5 \mathrm{~Hz}$ \\
Média & $796,9 \mathrm{~Hz}$ & $656,3 \mathrm{~Hz}$ & $187,5 \mathrm{~Hz}$ \\
\hline
\end{tabular}

Com os valores médios das frequências naturais de cada material, através do modelo matemático estabelecido pela norma [2], foi calculado o Módulo de Elasticidade. A Tabela 5 apresenta os valores calculados do módulo de elasticidade para cada material:

Tabela 5: Valores obtidos do módulo de elasticidade pelo método da norma ASTM E 1876

\begin{tabular}{c|c}
\hline Material & Módulo de Elasticidade \\
\hline Aço Domex 700 & $214,1 \mathrm{GPa}$ \\
Aço SAE 1522 & $199,76 \mathrm{GPa}$ \\
Alumínio & $76,1 \mathrm{GPa}$ \\
\hline
\end{tabular}

\subsection{Ensaio de tração}

A Figura 11 mostra os corpos de prova dos aços Domex 700 e SAE 1522 após o ensaio de tração onde pode ser visto o estrangulamento e as marcações para medir a variação de comprimento. Para comparar os resultados entre os dois métodos utilizados para medir o módulo de elasticidade, os corpos de prova para os ensaios de tração foram retirados daqueles usados para o ensaio de frequência e, em função das dimensões destes, não foi possível fabricar 6 corpos de prova conforme estabelecido pela norma ASTM E8M.

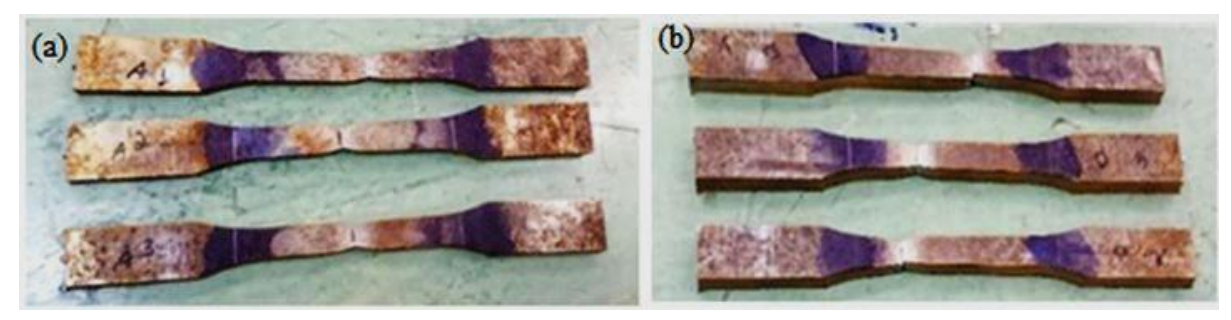


Figura 11: Corpos de prova após o Ensaio de Tração. (a) Aço SAE 1522 e (b) aço Domex 700.

A Tabela 6 mostra os dados dos ensaios de tração para os três corpos de prova do aço Domex 700 .

Tabela 6: Dados gerados no ensaio de tração no Aço Domex 700

\begin{tabular}{c|c|c|c|c|c}
\hline Amostra Domex 700 & CP 1 & CP2 & CP3 & Média & Desvio Padrão \\
\hline Tensão Máxima (MPa) & 799,75 & 822,3 & 804,36 & 808,803 & 11,913 \\
Tensão de Escoamento (MPa) & 785,394 & 808,69 & 784,318 & 792,800 & 13,771 \\
Alongamento Final (\%) & 13,43 & 13,28 & 15,31 & 14,006 & 1,131 \\
\hline
\end{tabular}

A Tabela 7 mostra os dados gerados dos ensaios de tração nos três corpos de prova do aço SAE 1522 .

Tabela 7: Dados gerados no ensaio de tração no Aço SAE 1522

\begin{tabular}{c|c|c|c|c|c}
\hline Amostra SAE 1522 & CP 1 & CP2 & CP3 & Média & Desvio Padrão \\
\hline Tensão Máxima (MPa) & 490,73 & 498,82 & 498,34 & 495,963 & 4,538 \\
Tensão de Escoamento (MPa) & 365,339 & 366,991 & 370,353 & 367,561 & 2,555 \\
Alongamento Final (\%) & 26,05 & 25,88 & 25,68 & 25,87 & 0,185 \\
\hline
\end{tabular}

A Tabela 8 apresenta, os dados gerados dos ensaios de tração nos três corpos de prova do Alumínio.

Tabela 8: Dados gerados no ensaio de tração no Alumínio

\begin{tabular}{c|c|c|c|c|c}
\hline Amostra Alumínio & CP 1 & CP2 & CP3 & Média & Desvio Padrão \\
\hline Tensão Máxima (MPa) & 147,08 & 147,31 & 137,44 & 143,9433 & 5,633 \\
Tensão de Escoamento (MPa) & 88,048 & 103,001 & 91,722 & 94,257 & 7,792 \\
Alongamento Final (\%) & 9,59 & 10,67 & 8,85 & 9,703333 & 0,915 \\
\hline
\end{tabular}

A Figura 12 mostra os valores médios da tensão e da deformação, obtidos no ensaio de tração do aço Domex 700, na região elástica onde o comportamento linear e a deformação são proporcionais à tensão.

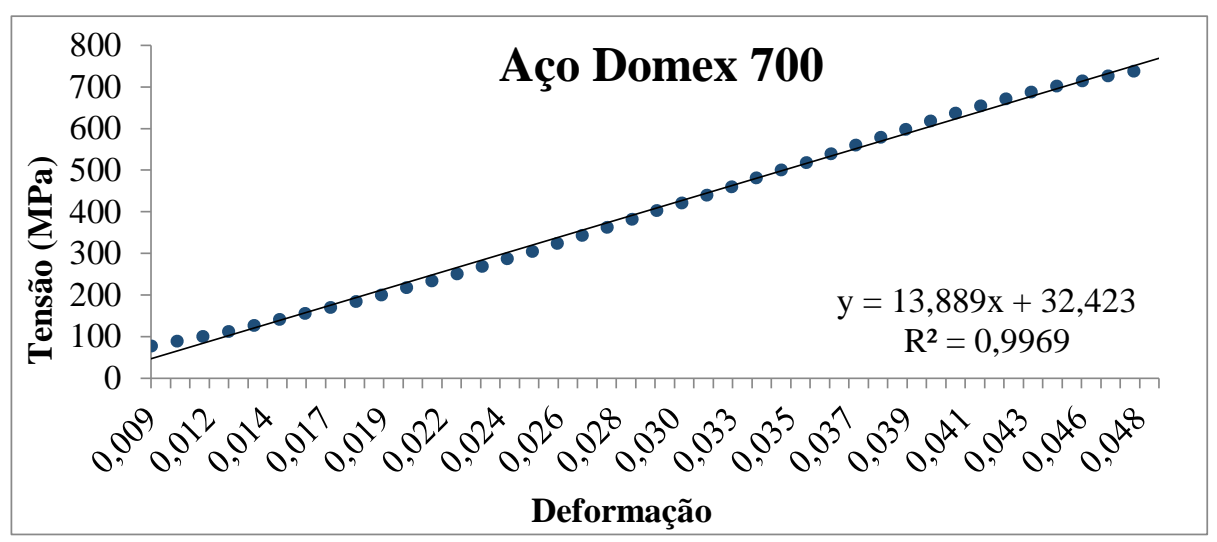

Figura 12: Curva Tensão-deformação média do aço Domex 700.

Pode ser visto na Figura 13 os valores médios da tensão e da deformação obtidos no ensaio de tração do aço SAE 1522, na região elástica onde o comportamento linear e a deformação é proporcional à tensão. 




Figura 13: Curva Tensão-deformação média do aço SAE 1522.

A Figura 14 mostra os valores médios da tensão e da deformação obtidos no ensaio de tração do Alumínio $1200 \mathrm{H} 14$, na região elástica onde o comportamento linear e a deformação são proporcionais à tensão.

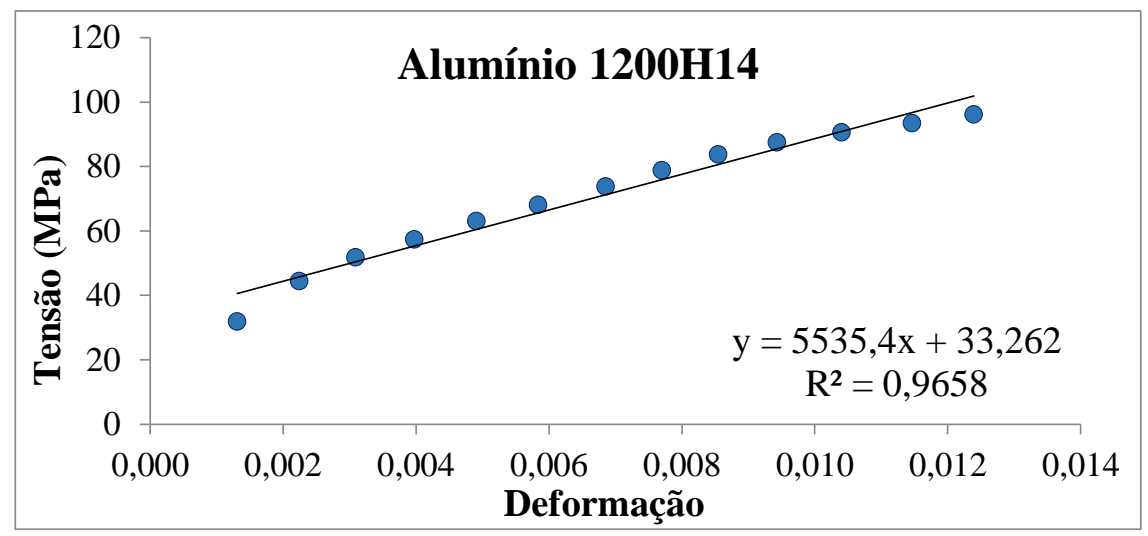

Figura 14: Curva Tensão-deformação média do Alumínio 1200H14.

A Tabela 9 apresenta os valores calculados do módulo de elasticidade no Ensaio de Tração nos três corpos de prova de cada material, e também a média e o desvio padrão.

Tabela 9: Valores calculados do Módulo de Elasticidade no Ensaio de Tração

\begin{tabular}{c|c|c|c}
\hline Ensaio & Aço Domex 700 & Aço SAE 1522 & Alumínio \\
\hline Amostra 1 & $205,58 \mathrm{GPa}$ & $204,87 \mathrm{GPa}$ & $70,80 \mathrm{GPa}$ \\
Amostra 2 & $207,75 \mathrm{GPa}$ & $202,45 \mathrm{GPa}$ & $72,76 \mathrm{GPa}$ \\
Amostra 3 & $208,28 \mathrm{GPa}$ & $202,05 \mathrm{GPa}$ & $70,42 \mathrm{GPa}$ \\
Média & $207,20 \mathrm{GPa}$ & $203,12 \mathrm{GPa}$ & $71,33 \mathrm{GPa}$ \\
Desvio Padrão & $1,43 \mathrm{GPa}$ & $1,53 \mathrm{GPa}$ & $1,26 \mathrm{GPa}$ \\
\hline
\end{tabular}

\subsection{Comparação dos Resultados e Discussão}

A partir dos resultados obtidos nos ensaio, é possível fazer a comparação e analisar qual método apresentou o melhor resultando. A figura 15 mostra o comparativo dos dados encontrados do módulo de elasticidade pelo método da norma ASTM E 1876 e pelo ensaio de tração, onde a diferença do aço Domex 700 entre os dois métodos foi de 2,97\%, a diferença do aço SAE 1522 foi de 1,35 e a diferença do Alumínio foi de 6,95\%. 


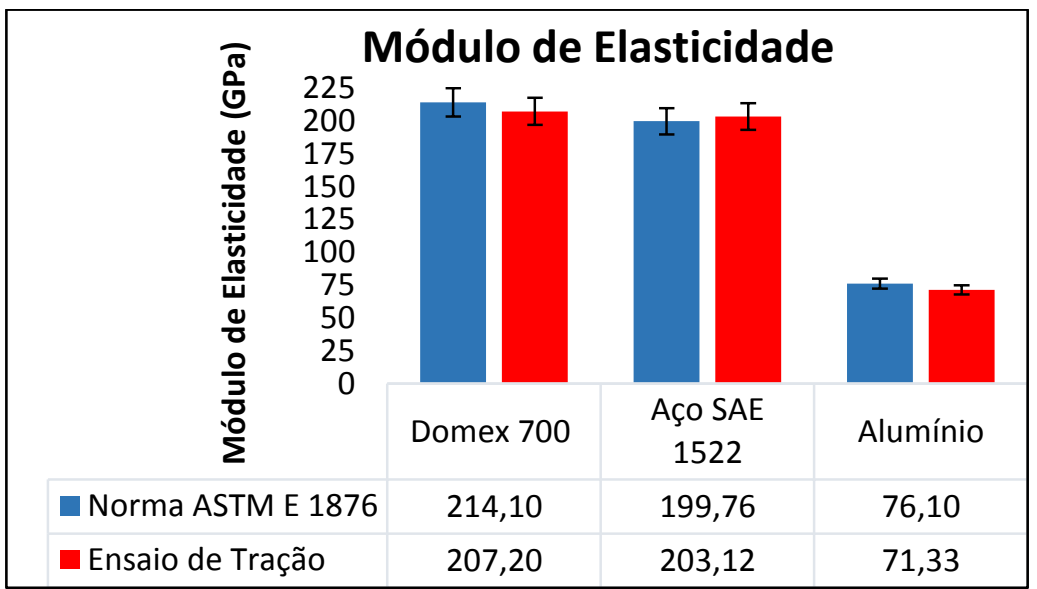

Figura 15: Comparativo do Módulo de Elasticidade entre a Norma ASTM E 1876 e o ensaio de tração.

A partir dos valores observados na Figura 15, é possível notar uma diferença não significativa entre os métodos aplicados no aço Domex, no aço SAE 1522 e no Alumínio. Deste modo, percebe-se que os resultados apresentaram pequena diferença entre os dois métodos.

No aço Domex, o método da norma ASTM E 1876 apresentou um valor pouco maior do que os valores calculados no ensaio de tração, possivelmente relacionados à posição em que o corpo de prova foi colocado no ensaio de vibração, ou, por outro lado, em função da precisão da máquina de ensaio de tração. Entretanto, a diferença entre os dois métodos, em percentual, não ficou maior que 3,22\%.

Para o aço SAE 1522, os valores encontrados ficaram muito próximos entre aquele obtido no ensaio de tração e o calculado pela norma ASTM E 1876, em comparação aos outros materiais analisados.

Para Alumínio, o método da norma ASTM E 1876 apresentou um valor maior do que os valores calculados no ensaio de tração, possivelmente devido ao corpo de prova ter uma pequena espessura $(2,5$ $\mathrm{mm}$ ), e possa ter flambado no processo de usinagem, ou mesmo por ser mais leve que os demais corpos de prova e assim sendo mais fácil de deslizar sobre os apoios, sofrendo possível interferência na captura das vibrações e consequentemente no módulo de elasticidade.

A utilização desse método possibilita medir o modulo de elasticidade de partes de máquinas e estruturas antigas (como uma ponte) onde não é possível remover partes para fazer análises, porém é necessário determinar as propriedades mecânicas daqueles materiais, quando for possível mensurar suas dimensões.

\section{CONCLUSÃO}

Com a metodologia utilizada neste trabalho foi possível validar o método de cálculo da frequência natural por impulso baseado na norma ASTM E1876 e determinar o módulo de elasticidade nos matérias propostos.

Pelo método de vibração por impulso baseado na norma ASTM E 1876 foi realizado os ensaios nos materiais propostos e obtido as frequências de vibração.

Através de fórmulas matemáticas e com o auxílio de uma planilha eletrônica foi possível determinar o módulo de elasticidade de cada material.

Com os dados gerados nos ensaios de tração, foi possível calcular e determinar o módulo de elasticidade do material.

Foram comparados os resultados entre o método de vibração por impulso e o ensaio de tração. No método de vibração por impulso conseguiu-se obter resultados semelhantes do módulo de elasticidade quando comparado ao ensaio de tração, de uma maneira rápida, não destrutiva, e de boa confiabilidade.

A aplicação da norma ASTM E 1876, apresenta vantagens se comparado ao ensaio de tração, principalmente por ser um ensaio não destrutivo, o custo é muito menor e os cálculos são realizados de maneira simples e rápida.

\section{BIBLIOGRAFIA}

[1] CALLISTER, JR., WILliAM D., Ciência e engenharia de materiais: uma introdução. Rio de Janeiro, LTC, 2012. 
[2] ASTM., Standard Test Method for Dynamic Young's Modulus, Shear Modulus, and Poisson's Ratio by Impulse Excitation of Vibratio - E 1876-00. USA, 2001.

[3] ALMEIDA, J. H. S., ANGRIZANI, C. C., BOTELHO, E. C., et al. "Effect of fiber orientation on the shear behavior of glass fiber/epoxy composites”, Materials \& Design (1980-2015), v. 65, 2015, pp. 789-795.

[4] BATISTA, N. L., et al. "Correlation between degree of crystallinity, morphology and mechanical properties of PPS/carbon fiber laminates”, Mat. Res., v.19, n.1, pp.195-201, 2016.

[5] BEZERRA, A.C.S., et. al., "Influência do Adensamento do Concreto nos Resultados de Módulo de Elasticidade", In: X Congreso Latinoamericano de Patologia y XII Congreso de Calidad en la Construcción, Valparaíso, 29 Sept. al 2 Oct. 2009.

[6] RAO, S. S., Vibrações mecânicas . São Paulo, Pearson Prentice Hall, 2008.

[7] BOROBIA, T. J., Elemento de Máquinas y Vibraciones. 3 Ed., Argentina, McGraw-Hill, 2012.

[8] GARCIA, A., SPIN, J. A., SANTOS, C. A. Ensaios dos materias. $2^{a}$ Ed., São Paulo, LTC, 2012.

[9] ALIATORE, D. G., Introdução à Mecatrônica e aos Sistemas de Medições. $4^{a}$ Ed., Porto Algre - RS: AMGH Editora LTda, 2014.

[10] FIGUEIREDO, L.J., GAFANIZ, A. R., LOPES, G. S., et al. Aplicações de Acelerómetros. Instrumentação e aquisição de sinais, Lisboa, 2007

[11] HBM. Disponivel em: https://www.hbm.com/pt/2261/mgcplus-sistema-de-aquisicao-de-dados-modular/. Acessado em: 22/10/2016

[12] ASTM. Standard Test Methods for Tension Testing of Metallic Materials - E 8M-09. USA, 2009.

\section{ORCID}

Mateus Henrique Mezzomo

Amauri Gomes de Moraes http://orcid.org/0000-0003-4049-9689

https://orcid.org/0000-0002-8841-5125 